\title{
Baker's cyst in children: conservative management versus surgical excision according to clinical and imaging criteria
}

\author{
Mohammed A. Mansour, Mohammed A. Shehata, Mohammed M. Shalaby, Mohammed A. Arafa and
} Hisham A. Almetaher

\begin{abstract}
Background: Pediatric patients rarely exhibit Baker's cysts. This study was conducted on 15 cases (9 males, 6 females) presented with Baker (popliteal) cyst in the last 2 years (from September 2017 to September 2019). The mean age was 8.5 years. The aim of this study was to present our experience in management of these cases based on clinical and imaging criteria. Plain $x$-ray and knee ultrasonography were routinely done for all cases. If the size of the cyst was less than or equal to $3 \mathrm{~cm}$ by ultrasonography, with no or minimal pain, the patients were managed conservatively and were scheduled to followed up visits after 3 months, 6 months, and after 12 months for clinical assessment of symptoms and sonographic size of the cyst. Surgical excision of the Baker's cyst was considered if the size of the cyst was more than $3 \mathrm{~cm}$ with persistent of pain.
\end{abstract}

Results: Seven cases had cysts less than $3 \mathrm{~cm}$ by ultrasonography and were managed conservatively. In five out of these seven cases, the cysts disappeared with no recurrence within the first year of follow-up. In two cases, the cysts increased in size with increase in pain. These two cases were subjected to surgical excision after 1 year of follow-up.

The remaining eight cases had cysts more than $3 \mathrm{~cm}$ and were managed by surgical excision.

Out of the ten cases which were managed by surgical excision, recurrence occurred in 3 cases within the first postoperative year (after 4 months, 7 months, and 8 months) consecutively.

Conclusions: The management of Baker's cysts in children is debatable, with no definite protocol. In this current study, we conclude that surgical excision of large Baker's cysts (more than $3 \mathrm{~cm}$ ) with persistent symptoms is crucial providing meticulous dissection without rupture of the cyst and proper closure of the pedicle which connects the cyst with the knee joint, while conservative management and follow-up is effective in small Baker's cysts (less than $3 \mathrm{~cm}$ ) with no recurrence.

Keywords: Baker's cysts, Children, Conservative, Excision and recurrence

\section{Background}

Baker's cyst is a distended gastrocnemiussemimembranosus bursa. The first description of Baker's cysts is referred to Adams in 1840, while Baker studied these cysts in the context of intra-articular pathologies and effusion of the knee joints [1].

* Correspondence: mohamad_awad44@yahoo.com

General Surgery Department, Faculty of Medicine, Tanta University, Tanta, Egypt
Pediatric patients rarely exhibit Baker's cysts. The incidence of Baker's cyst represents $2.4 \%$ in small prospective screening populations [2]. There is still a debate whether Baker's cysts or popliteal cysts in children communicate or not with the internal joint space [3].

It is necessary to explain the disease to the child's guardians to decrease their anxiety in relation to the presence of the cyst. Baker's cyst does not require surgical management in the majority of patients; however, in

\section{Springer Open}

(c) The Author(s). 2021 Open Access This article is licensed under a Creative Commons Attribution 4.0 International License, which permits use, sharing, adaptation, distribution and reproduction in any medium or format, as long as you give appropriate credit to the original author(s) and the source, provide a link to the Creative Commons licence, and indicate if changes were made. The images or other third party material in this article are included in the article's Creative Commons licence, unless indicated otherwise in a credit line to the material. If material is not included in the article's Creative Commons licence and your intended use is not permitted by statutory regulation or exceeds the permitted use, you will need to obtain permission directly from the copyright holder. To view a copy of this licence, visit http://creativecommons.org/licenses/by/4.0/. 
children with Baker's cyst who were managed conservatively, there is partial or total remission of the growth in approximately half of these patients [4].

Surgical excision is the preferred decision in children presented with persistent painful symptoms. The procedure is carried out under general anesthesia with the patient in prone position, through a transverse incision in the popliteal fold, following the skin lines, dissecting all around the cyst. Once the base of the cyst was identified, excision and closure of the remaining orifice was done by absorbable suture in purse string fashion [5].

Till now, there is no consensus about the ideal management of Baker's cysts in children and many controversies were reported between surgical excision against conservative management [5].

The aim of this study was to present our experience in management of these cases based on clinical and imaging criteria.

\section{Methods}

Children presented with Baker's (popliteal) cyst in the period from September 2017 to September 2019 were included in this study. Ethical committee requirements were fulfilled. Guardians of each patient were informed about all steps in this study including initial evaluations, management plan, operative details, and follow-up protocol. Informed consent was taken from parents of each patient who included in the study.

Plain $\mathrm{x}$-ray and knee ultrasonography were routinely done for all cases. Additional subsidiary imaging studies were not usually necessary in this study. Knee ultrasonography showed cyst content, distinguished cysts with liquid contents from solid masses, and detected the size and location of the Baker's cyst.

\section{Protocol of management \\ Conservative management}

Conservative management in form of non-steroidal antiinflammatory drugs was applied on children presented by Baker's cysts less than or equal $3 \mathrm{~cm}$ which were measured by ultrasonography and associated with minimal pain.

Follow-up by clinical assessment and knee ultrasonography was done after 3 months, 6 months, and after 12 months. In patients who did not improve on this conservative management or revealed increase in the size of the cyst more than $3 \mathrm{~cm}$, surgical excision was performed.

\section{Surgical excision}

Surgical excision was considered if the size of the Baker's cyst was more than $3 \mathrm{~cm}$ with persistent symptoms and pain which was not relieved by non-steroidal antiinflammatory drugs (Fig. 1).

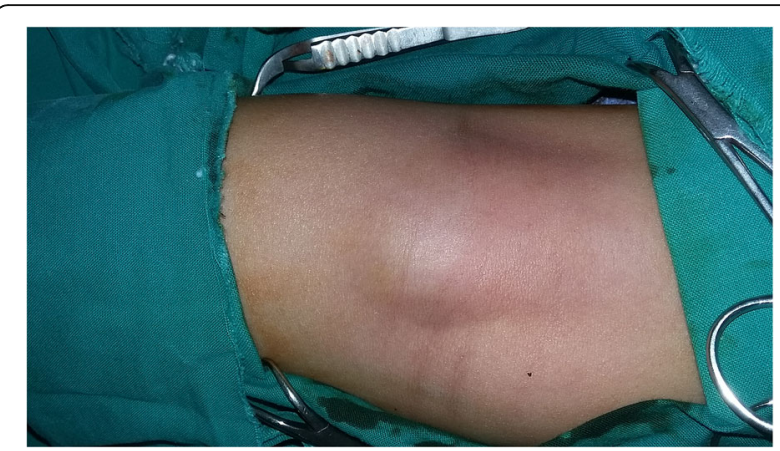

Fig. 1 Baker cyst

\section{Surgical procedure}

Under general anesthesia while the patient was in prone position; a lazy $S$ incision in the popliteal fold was done. Meticulous dissection of the cyst was done using combined blunt with sharp dissection to avoid rupture of the cyst (Figs. 2 and 3). Once the base was reached, excision was done and the residual orifice was closed with purse string stitches using long-lasting absorbable suture (P.D.S. 5/0) in two layers. The excised cyst was sent for histopathological examination.

\section{Results}

Fifteen patients (9 males, 6 females) were included in this study. Eleven patients presented with right side cysts, and 4 patients presented with the left side cysts. The mean age of patients was 8.5 years (range from 6 to 14 years) (Table 1 ).

Baker's cysts less than $3 \mathrm{~cm}$ were reported in seven cases and underwent conservative management. Conservative treatment was succeeded in five cases; two cases showed disappearance of the cyst after 3 months, two cases after 6 months, and one case after 12 months. Follow-up for these cases for 9 months showed no recurrence.

The cysts increased in size with persistent pain in two cases which underwent conservative management (one

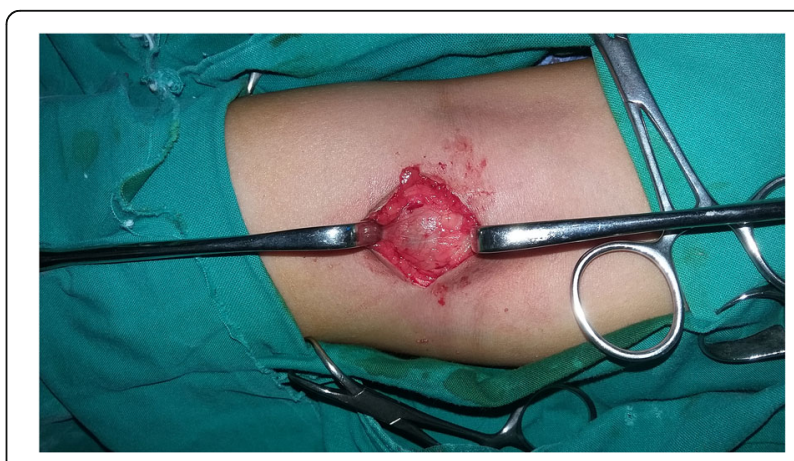

Fig. 2 Dissection of the cyst 


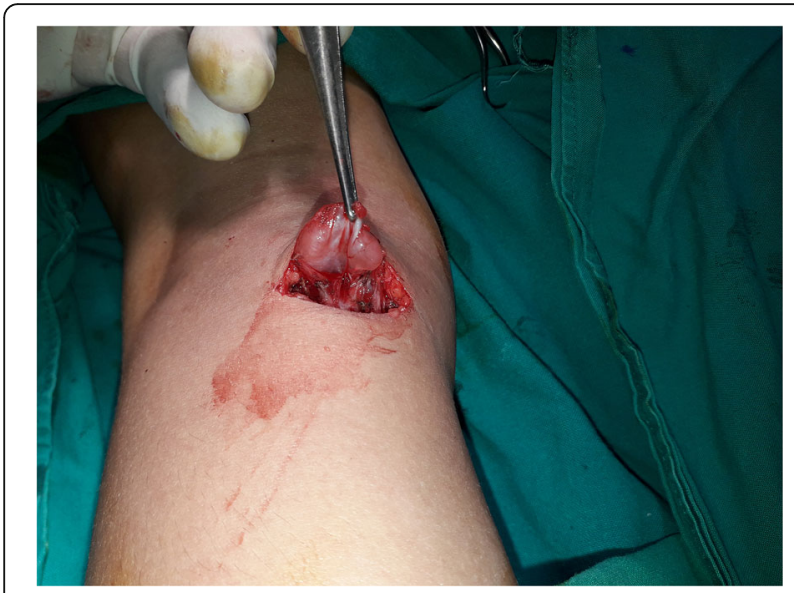

Fig. 3 Dissected Baker cyst

case became $6 \mathrm{~cm}$; the other case became $7 \mathrm{~cm}$ ), so surgical excision was performed.

Baker's cysts more than $3 \mathrm{~cm}$ were reported in eight cases by ultrasonography measures with a mean size of $9 \mathrm{~cm}$ (ranged from 7 to $12 \mathrm{~cm}$ ). Surgical excision was done to all of them.

All patients were followed up in the outpatient clinic 2 weeks, 3 months, 6 months, and 9 months after the surgery. Guardians of the patients were advised to contact the department of pediatric surgery if there were any concerns in the immediate post-operative period. Knee ultrasonography was done for all patients at the visits of follow-up.

Out of the ten cases which were managed by surgical excision ( 8 cases with cysts more than $3 \mathrm{~cm}$, and 2 cases with failure of conservative management), recurrence occurred in 3 cases within the first post-operative year (after 4 months, 7 months, and 8 months) consecutively (Fig. 4).

Redo surgery was done after 6 months from the time of recurrence. Those patients were followed up in outpatient clinics for another 6 months with no recurrence (Table 2).

Table 1 Demographic data of the cases

\begin{tabular}{lll}
\hline No. of cases & & \\
\hline Sex & Male & 9 \\
& Female & 6 \\
Age & 6-8years & 4 \\
& 8-10 years & 8 \\
& 10-14 years & 3 \\
Site & Right & 11 \\
& Left & 4 \\
\hline
\end{tabular}

Nine cases out of our cases were male; eight of the studied cases were from 8 to 10 years, and 11 cases presented with right side Baker cyst

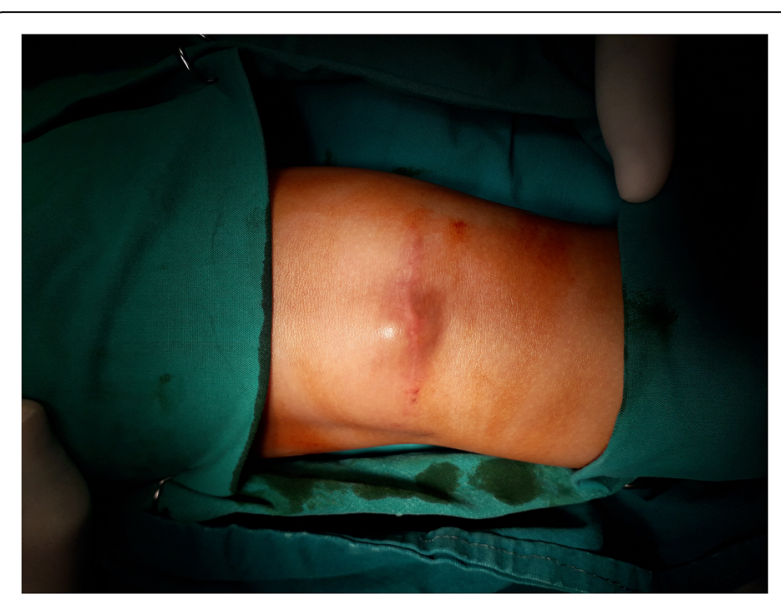

Fig. 4 Recurrent Baker cyst

\section{Discussion}

There is a debate in management of Baker's cyst in children as many studies showed a lower incidence of Baker's cysts in children of less than 1 to $10 \%[6,7]$.

Due to the limitation in guidelines for management of Baker's cysts in children, the current study was performed to present our experience in management of these cases based on clinical and imaging criteria.

De Maeseneer et al. [8] reported that history of trauma may not be a frequent cause of Baker's cyst especially in children. It may be presented with no definite pathological cause in children and in this current study, we agreed with their hypothesis and no case was detected with history of previous trauma.

Baker's cysts may be detected at any age but one third of cases were reported to occur within the first 15 years of life [9]. Smith et al. reported that the condition is more common unilaterally, more common in boys, and has a peak age of occurrence between 2 and 14 years [10]. These results were agreed with our current study and studied cases.

In agreement with the current study, Baker's cyst in children is seldom associated with joint effusion, meniscus tear, or anterior cruciate ligament tear. Typically, there is no history of prior knee injury or symptoms of intra-articular pathology in children suffering from Baker's cysts [8]..

Ultrasonography is an effective imaging modality to assess the musculoskeletal system. With good experience, ultrasonography can be a time-efficient and economical imaging tool for the medical assessments of the knee [11]. Ultrasonography has various advantages; it offers availability of appropriate images and more accurate to detect any communication of the cyst with the knee joint. MRI is the next best choice if the findings are unusual on ultrasonography images [12]. We did not request knee MRI for any cases in the current study and 
Table 2 Follow-up of the studied cases

\begin{tabular}{llll}
\hline & No. of cases managed conservatively & No. of cases improved conservatively & $\begin{array}{l}\text { No. of cases needed } \\
\text { operation }\end{array}$ \\
\hline $\begin{array}{l}\text { No. of } \\
\text { cases }\end{array}$ & 7 & 5 & 2 \\
& $\begin{array}{l}\text { No. of cases managed surgically from } \\
\text { the start }\end{array}$ & $\begin{array}{l}\text { No. of cases managed surgically after failure of conservative } \\
\text { management }\end{array}$ & $\begin{array}{l}\text { No of recurrent cases after } \\
\text { surgery }\end{array}$ \\
$\begin{array}{l}\text { No. of } \\
\text { cases }\end{array}$ & 8 & 2 & 3
\end{tabular}

Seven cases were managed conservatively, and five of them improved, while 2 cases needed surgery in addition to the eight cases which were operated from the start; a total 10 cases were managed surgically. Recurrence was reported in 3 cases

we depended on ultrasonography findings. MRI is more accurate in describing the relation of the cyst (either communicated or not) with the knee joint and consequently the cause of recurrence but in the current study, we tried to standardize the imaging tool for diagnosis and follow-up. Knee ultrasonography is a time-efficient, cheap, safe, and available tool for imaging for Baker's cyst.

The natural history of Baker's cysts among children appears to have good prognosis. In many literatures, more than 53\% of Baker's cysts among children were treated conservatively and revealed complete resolution subsequently [13, 14]. De Greef hypothesized that Baker's cysts among children typically disappeared before the age of 18 years. It may be reasonable to expect good results following conservative treatment [13].

Surgical excision is necessary in some children suffering from Baker's cyst, although some reported that surgery for Baker's cysts in children presents unnecessary risks and the high post-operative recurrence rates reaching up to 42 to $50 \%$ in some literatures [14].

The indications for surgery include persistent knee pain, knee effusion, progressive increase in size of the cyst, limitation of motion, and rupture of the cyst [13].

The original surgical procedure described by Van Demark and Meyer involved the removal of the cyst and the primary closure of the pedicle connecting the cyst with the joint capsule and had been plagued with a high rate of recurrence [15].

In the current study, the recurrent cases after surgical removal occurred in the first cases because of rupture of the cyst and inability to close the connection between the cyst and the knee joint and closure and using vicryl sutures, we tried to decrease the recurrence rate by closure of the residual orifice with purse string stitches using long-lasting absorbable (P.D.S. 5/0) in two layers after meticulous dissection and excision of the cyst.

The post-operative care following surgery is important for optimal recovery; the affected limb should be immobilized and protected for a period of time and limitation of wide range of movement [16].

\section{Conclusions}

The management of Baker's cysts in children is debatable, with no definite protocol. In this current study, we conclude that surgical excision of large Baker's cysts (more than $3 \mathrm{~cm}$ ) with persistent symptoms is crucial, providing meticulous dissection without rupture of the cyst and proper closure of the pedicle which connects the cyst with the knee joint, while conservative management and follow-up is effective in small Baker's cysts (less than $3 \mathrm{~cm}$ ) with no recurrence.

\section{Acknowledgements \\ Not applicable}

\section{Authors' contributions}

All authors have read and approved the final version of the manuscript. MAM wrote the paper with revision and the corresponding author. HAM gave the idea and collected the patients' data and analyzed them. MAS, MMS, and MAA put the study design and followed the patients postoperatively.

\section{Authors' information}

Not applicable

Funding

This study had no funding from any resource.

\section{Availability of data and materials}

The datasets used and/or analyzed during the current study are available from the corresponding author on reasonable request.

\section{Ethics approval and consent to participate}

This current study was approved by the institute's research ethics committee of faculty of medicine, Tanta University, Egypt. All patients included in this study gave written informed consent to participate in this research by their parent or legal guardian with complete idea about the protocol and followup of the study and each patient had a serial number in his admission file to facilitate the follow-up. The serial number of every case in the study was arranged serially and documented in each patient's file for any need from ethical committee.

\section{Consent for publication}

All patients included in this research gave written informed consent to publish the data contained within this study by their parent or legal guardian.

\section{Competing interests}

All authors have no conflicts of interest or financial ties to disclose. Content has not been published elsewhere, and the paper has not been submitted elsewhere. 
Received: 29 September 2020 Accepted: 11 January 2021

Published online: 09 February 2021

\section{References}

1. Janzen DL, Peterfy CG, Forbes JR, Tirman PFJ, Genant HK. Cystic lesions around the knee joint: MR imaging findings. Am J Roentgenol. 1994;163(1): $155-61$.

2. Seil R, Rupp S, Jochum P, Schofer O, Mischo B, Kohn D. Prevalence of popliteal cysts in children. A sonographic study and review of the literature. Arch Orthopaedic Trauma Surg. 1999;119(1-2):73-5.

3. Touloukian RJ. Popliteal cysts in childhood. Surgery. 1971;69(4):629-32.

4. Van Rhijn LW, Jansen EJ, Pruijs HE. Long-term follow-up of conservatively treated popliteal cysts in children. J Pediatr Orthop B. 2000;9(1):62-4.

5. Chen JC, Lu CC, Lu YM, Chen CH, Fu YC, Hunag PJ, et al. A modified surgical method for treating Baker's cyst in children. Knee. 2008;15(1):9-14

6. Cellerini M, Salti S, Trapani S, D'Elia G, Falcini F, Villari N. Correlation between clinical and ultrasound assessment of the knee in children with monoarticular or pauciarticular juvenile rheumatoid arthritis. Pediatric Radiol. 1999. 29(2):117-23.

7. Rennebohm RM, Towbin RB, Crowe WE, Levinson JE. Popliteal cysts in juvenile rheumatoid arthritis. Am J Roentgenol. 1983;140(1):123-5.

8. De Maeseneer M, Debaere C, Desprechins B, Osteaux M. Popliteal cysts in children: prevalence, appearance and associated findings at MR imaging. Pediatric Radiol. 1999;29(8):605-9.

9. Lang IM, Hughes DG, Williamson JB, Gough SG. MRI appearance of popliteal cysts in childhood. Pediatr Radiol. 1997:27:130-2.

10. Smith JT, Yandow SM. Benign soft-tissue lesions in children. Orthop Clin North Am. 1996;27:645-54.

11. Friedman L, Finlay K, Jurriaans E. Ultrasound of the knee. Skeletal Radiol. 2001:30:361-77.

12. O'Connor D, Clarke NMP, Hegarty SE, Fairhurst JJ. The natural history of popliteal cysts in children: an ultrasound study. Knee. 1998;5:249-51.

13. De Greef I, Molenaers G, Fabry G. Popliteal cysts in children: a retrospective study of 62 cases. Acta Orthop Belg. 1998;64:180-3.

14. Stolle LB, Hvass I. Baker's cysts in children. A retrospective study at the hospitals in the county of Rebe from 1992 to 1998. Ugeskr Laeger. 2000;162: 5216-8.

15. Dlabach JA. Nontraumatic soft tissue disorders. In: Canale ST, editor. Campbell's operative orthopaedics. 10th ed. St Louis: Mosby-Year Book; 2003. p. 885-904.

16. Kannus P, Parkkari J, Jarvinen TL, Jarvinen TA, Jarvinen M. Basic science and clinical studies coincide: active treatment approach is needed after a sports injury. Scand J Med Sci Sports. 2003;13:150-4.

\section{Publisher's Note}

Springer Nature remains neutral with regard to jurisdictional claims in published maps and institutional affiliations.

\section{Submit your manuscript to a SpringerOpen ${ }^{\circ}$ journal and benefit from:}

- Convenient online submission

- Rigorous peer review

- Open access: articles freely available online

- High visibility within the field

- Retaining the copyright to your article

Submit your next manuscript at $\boldsymbol{\nabla}$ springeropen.com 